\title{
Hydrogeochemical Characteristics and Evolution of Hot Springs in Eastern Tibetan Plateau Geothermal Belt, Western China: Insight from Multivariate Statistical Analysis
}

\author{
Zheming Shi, ${ }^{1,2}$ Fu Liao, ${ }^{1}$ Guangcai Wang, ${ }^{1}$ Qingyu Xu, ${ }^{1}$ Wenqing Mu, ${ }^{1}$ and Xiaoyi Sun ${ }^{1}$ \\ ${ }^{1}$ MOE Key Laboratory of Groundwater Circulation and Environmental Evolution, China University of Geosciences, \\ Beijing 100083, China \\ ${ }^{2}$ School of Water Resources and Environment, China University of Geosciences, Beijing 100083, China \\ Correspondence should be addressed to Zheming Shi; szm@cugb.edu.cn
}

Received 10 March 2017; Accepted 14 May 2017; Published 4 June 2017

Academic Editor: Deepesh Machiwal

Copyright @ 2017 Zheming Shi et al. This is an open access article distributed under the Creative Commons Attribution License, which permits unrestricted use, distribution, and reproduction in any medium, provided the original work is properly cited.

\begin{abstract}
The eastern Tibetan Plateau geothermal belt is one of the important medium-high temperature geothermal belts in China. However, less work has been done on the hydrochemical characteristic and its geological origin. Understanding the chemical characteristics and the hydrochemical evolution processes is important in evaluating the geothermal energy potential in this area. In the present study, we discussed the hydrochemical properties and their origins of 39 hot springs located in the eastern Tibetan Plateau geothermal belt (Kangding-Litang-Batang geothermal belt). Cluster analysis and factor analysis are employed to character the hydrochemical properties of hot springs in different fault zones and the possible hydrochemical evolution processes of these hot springs. Our study shows that the hot springs can be divided into three groups based on their locations. The hot springs in the first group mainly originate from the volcanic rock and the springs in the second group originate from the metamorphic rock while the springs in the third group originate from the result of mixture of shallow water. Water-rock interaction, cation exchange, and the water environment are the three dominant factors that control the hydrochemical evolution process in the eastern Tibetan Plateau. These results are also in well agreement with the isotopic and chemical analysis.
\end{abstract}

\section{Introduction}

The collision between the Indian and Eurasian continents creates one of the largest orogens, the Tibetan-Himalayan orogen, worldwide [1]. Two syntaxes formed in the east and west of the Himalayan Mountain belt as a result of indentation of Indian continent into the Eurasian continent. Near the Eastern Himalayan syntaxis, the trend of mountains and rivers transitions from a near east-west direction to a southward direction toward India. As one of the important medium-high temperature geothermal belts in China, the eastern Tibetan Plateau geothermal belt (also called Kangding-Litang-Batang geothermal field) is located in the northeast of this region [2]. A number of hot springs with temperature range within $15^{\circ} \mathrm{C} \sim 90^{\circ} \mathrm{C}$ are distributed along different fault zones and attracted numerous tourists every year. Many of these hot springs have been developed by the local government and residents by being equipped with facilities of springs. Some of the springs have become famous tourism resorts. On the other hand, as a renewable and clean energy, geothermal energy can be used as electricity generation or heating. The Chinese Government has decided to exploit the geothermal energy in these areas in the 13th Five Year Plan (http://www.sdpc.gov.cn/zcfb/zcfbghwb/201702/t20170204_ 837204.html).

The basic physical and chemical properties of the hot springs in the eastern Tibetan Plateau geothermal belt have been investigated by Peking University and Chinese Academic of Sciences in the 1980s [3]. And several previous studies had studied the chemical characteristics of some springs in part of the geothermal field, which were mainly focused in some area [4-7]. Recently, Tang et al. [2] documented the extensive distribution of hot springs in the eastern Tibetan 


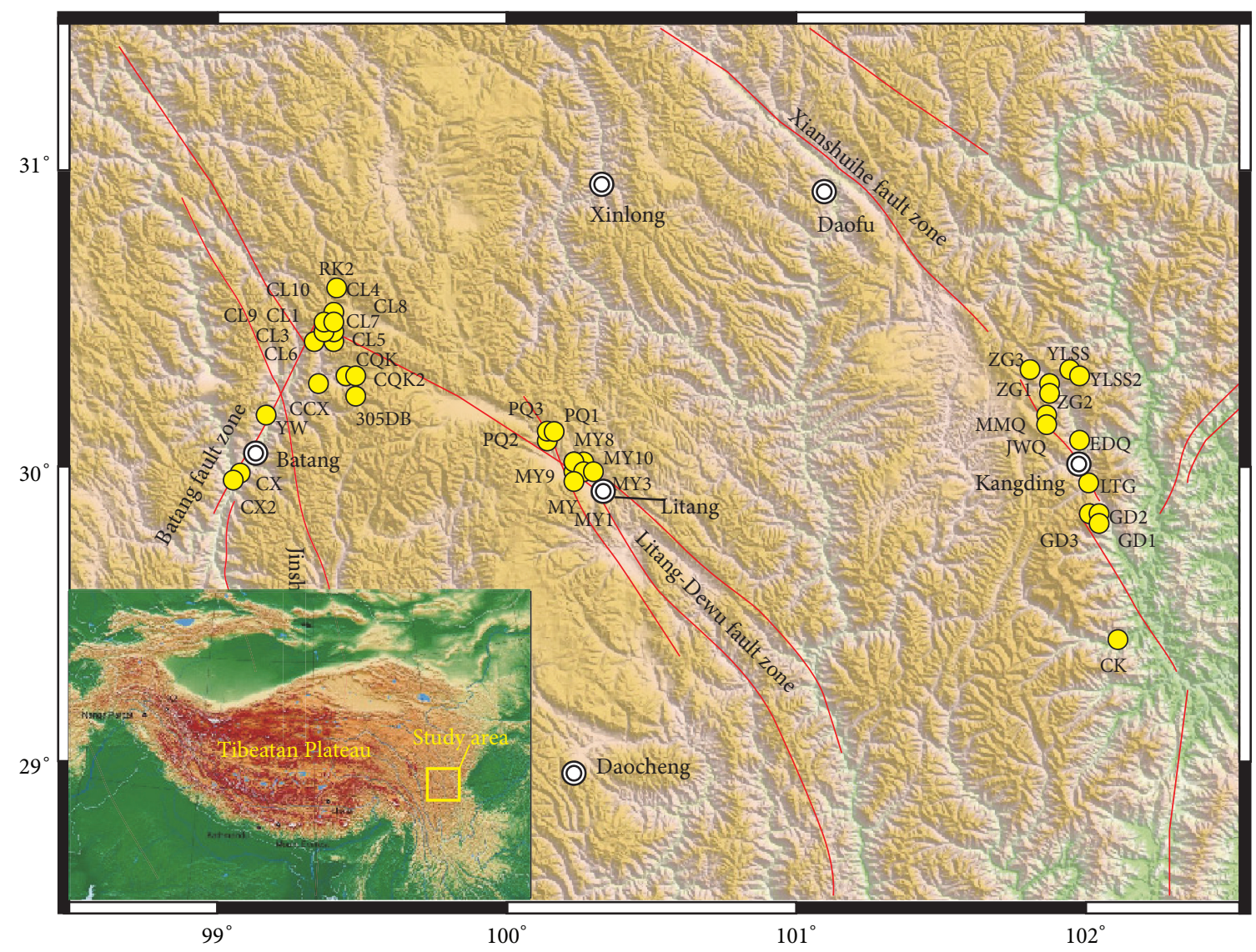

FIGURE 1: Geological setting of the study area.

Plateau and analyzed the origin of the heat source from the geological setting. However, less work has been done on the hydrochemical characteristic and its geological origin. Such study is important in evaluating the geothermal energy potential.

A multivariate statistical technique is an effective tool of interpreting a relationship between hydrochemistry and origin of springs [8-11]. Cluster analysis, factor analysis (FA), and principal components analysis (PCA) have been successfully used in characterizing geochemical data and the hydrochemical evolution of the groundwater [9, 12-16]. Among these, cluster analysis is effective in charactering the geochemical properties of the groundwater [17] and PCA method is commonly used in identifying the hydrochemical processes $[18,19]$. Factor analysis (FA) can be used to identify the major factors that controlled the geochemical process $[20,21]$.

In the study, we discuss the hydrochemical properties and their origins of 39 hot springs located in the eastern Tibetan Plateau geothermal belt. Cluster and factor multivariate statistical methods are employed to character the hydrochemical properties of hot springs in different fault zones and the possible hydrochemical evolution processes of these hot springs.

\section{Materials and Methods}

2.1. Geological Setting. The study area $\left(98.5^{\circ}-102.5^{\circ} \mathrm{E}\right.$, $28.5^{\circ}-31.5^{\circ} \mathrm{N}$ ), shown in Figure 1, is located in the northeast of the Eastern Himalayan syntaxis. This area is part of the Songpan-Ganzi complex, which is generally $4000 \mathrm{~m}$ above the sea level with peaks higher than $7 \mathrm{~km}$ (Konga mountain) and deep-cutting gorges (sanjiang) [22]. The longmenshan and Jinsha faults are the eastern and western boundaries of the Kangding-Litang-Batang highland, and the three major fault zones developed internally are the Xianshuihe fault, the Litang-Dewu fault, and the Batang fault (Figure 1). The Xianshuihe fault is a left-lateral strike-slip fault that emanates from Tibet with length more than $1000 \mathrm{~km}$. It penetrates the whole lithosphere and incise the upper mantle [23]. As one of the world's most active faults, at least 10 earthquakes with magnitude larger than 7 have occurred along a $350 \mathrm{~km}$ segment of the XFZ [24]. With length of approximately $385 \mathrm{~km}$, the Litang-Dewu fault is also a left-lateral strike-slip fault with nearly vertical slip [25], and it is almost parallel to the Xianshuihe fault. The Batang fault is a dextral slip fault with a length of about $200 \mathrm{~km}$ and a strike of $\mathrm{N} 30^{\circ}$ [26]. There are extensive occurrences of magmatic rocks in the Kangding-Litang-Batang highland, with reported granites focused in the Middle Triassic (220-230 Ma), the Jurassic 
(160-190 Ma) to Cretaceous (71-94 Ma), and the Cenozoic (13-41 Ma).

2.2. Hot Springs. Many hot springs exist in the eastern Tibetan Plateau, and we mainly concentrated on three geothermal fields in our study: Kangding geothermal field, Litang geothermal field, and Batang geothermal field. These springs are controlled by the Xianshuihe, Litang, and Batang fault zone and are usually occurring along the major or secondary fault zones (Figure 1).

In the Kangding geothermal field, hot springs are mainly located in Zhonggu and Yunlinggong hot water zone. These springs are linearly distributed along the Kangding-Moxi fault zone-secondary fault zone of the Xianshuihe fault zone. The spring temperatures in this hot water zone are controlled by the tectonic setting and aquifer lithology. In the Kangding geothermal field, the springs exposed in the crystallized limestone show lower temperature (the temperature at EDQ springs is mostly around $40^{\circ} \mathrm{C}$ ) and show high temperature in the contact zone with granite (i.e., the spring temperature of Yulingong hot water zone can be as high as $91^{\circ} \mathrm{C}$; also the temperature in ZK201 geothermal well in this area can reach $208^{\circ} \mathrm{C}$ at the bottom depth of $267 \mathrm{~m}$ [2]). In Litang geothermal field, the springs are located along Litang fault and exposed by the fractures within the contact zone of granites, limestone, and andesite-basalt. The springs are mainly located in Maoya, Qukailong, with temperature higher than $60^{\circ} \mathrm{C}$. In Batang geothermal field, springs are located along the fault zone and the spring temperatures are different in the south and north parts: lower temperature in the south part and higher temperature in the north part. In the north part, the hot springs are mainly occurring in the junction zone of Litang and Batang fault, and the temperature in this area can be as high as the local boiling temperature. The springs in the south part are mostly exposed in crystallization dolomitic limestone and schist, whereas in the north part they are exposed in the contact zone of granite, sand slate, and limestone.

2.3. Sampling. We collected water samples for hydrogen and oxygen stable isotope analysis from 39 hot springs in July 2016 in this area (Figure 1). Samples for stable isotope analysis were collected and stored in $50 \mathrm{ml}$ polyethylene bottles, while the samples for chemical analysis were collected and stored in two $250 \mathrm{ml}$ polyethylene bottles. All the water chemical samples were filtered through $0.45 \mu \mathrm{m}$ membranes on site. For cation analysis, reagent-grade $\mathrm{HNO}_{3}$ with molar concentration up to $14 \mathrm{M}$ was added to the sample collected at each site to bring the $\mathrm{pH}$ below 1. $\mathrm{pH}$ and TDS were determined by the Clean M30 pen-type tester in the field. Water temperatures were measured in the field with a digital thermometer with accuracy of $0.1^{\circ} \mathrm{C}$. The major ions were analyzed by means of ion chromatography (Dionex-900). Stable isotopes of oxygen-18 and deuterium were analyzed with the liquid-water isotope analyzer-LGR, with accuracy of $0.2 \%$ for $\delta^{18} \mathrm{O}$ and $0.3 \%$ for $\delta \mathrm{D}$. The $\mathrm{CO}_{3}{ }^{2-}$ and $\mathrm{HCO}_{3}{ }^{-}$ concentrations were measured by potentiometric titrator. The $\mathrm{SO}_{4}{ }^{2-}$ and $\mathrm{Cl}^{-}$concentrations were determined on an unacidified sample by ion chromatography. The $\mathrm{Ca}^{2+}, \mathrm{Mg}^{2+}$, $\mathrm{Na}^{+}$, and $\mathrm{K}^{+}$concentrations were analyzed by ICP-AES and the other metal elements by ICP-MS within 2 weeks after sampling. All of the chemical analysis was completed by Sinomine Rock and Mineral Analysis Co. Ltd. The hydrochemistry of all water samples is summarized in Table 1. Cluster analysis and factor analysis were used in data analysis in order to understand the chemical characteristic and hydrochemical evolution process of these hot springs.

2.4. Statistical Analysis. Cluster analysis (CA) and factor analysis (FA) are used to identify the characteristics of the hydrochemical properties of hot springs in different fault zones and the possible hydrochemical evolution processes of these hot springs. Cluster analysis groups a system of variables into clusters on the basis of similarities (or dissimilarities) such that each cluster represents a specific process in the system. In this study, the $K$-means clustering was applied to the raw data. In $K$-means clustering, clusters are represented by a central vector, which may not necessarily be a member of the dataset. When the number of clusters is fixed to $k, k$-means clustering gives a formal definition as an optimization problem: find the $k$ cluster centers and assign the objects to the nearest cluster center, such that the squared distances from the cluster are minimized [27].

Factor analysis is a multivariate analytical technique, which derives a subset of uncorrelated variables called factors that explain the variance observed in the original dataset. Factor analysis is used to uncover the latent structure of a set of variables. In technical terms, common factor analysis represents the common variance of variables, excluding unique variance, and is thus a correlation-focused approach seeking to reproduce the intercorrelation among the variables. Factor analysis can be performed on any kind of scientific data to establish a pattern of variation among variables or reduce large datasets into factors for easy handling and interpretation [28].

\section{Results}

3.1. Hydrochemistry. The chemical types of the hot springs are dominant by Na-HCO3 type (Table 1, Figure 2); only a few springs show other types; that is, $\mathrm{Na}-\mathrm{Ca}-\mathrm{SO}_{4}$ occurred in CL7 hot spring; $\mathrm{Ca}-\mathrm{Na}-\mathrm{HCO}_{3}$ occurred in CK hot spring. The TDS ranges within $0.27 \mathrm{~g} / \mathrm{L} \sim 1.949 \mathrm{~g} / \mathrm{L}$ of the hot springs. Thus, most samples contain $\mathrm{Na}^{+}$and $\mathrm{HCO}_{3}{ }^{-}$and are the predominant ions whereas their $\mathrm{Ca}^{2+}$ and $\mathrm{Mg}^{2+}$ concentration are generally low. High $\mathrm{B}, \mathrm{Li}$, and $\mathrm{F}$ are found in these springs (Table 1). The temperature ranges within $25.6^{\circ} \mathrm{C} \sim 89^{\circ} \mathrm{C}$ with $\mathrm{pH}$ ranges within 6.1 8.9. High temperature springs can be found in each geothermal field. Springs with $\mathrm{pH}$ larger than 8 are mainly distributed in CL1, CL3, CL4, CL5, CL6, CL7, CL8, CL9, CL10, and RK2 springs and PQ1, PQ2, and PQ3 springs. High TDS are mainly found in the Litang geothermal field. High $\mathrm{HCO}_{3}{ }^{-}$and $\mathrm{Na}^{+}$are mainly located in the Litang geothermal and high $\mathrm{Cl}^{-}$in the Kangding geothermal field.

3.2. Isotope. The isotope compositions of $\mathrm{H}$ and $\mathrm{O}$ were displayed on the $\delta \mathrm{D}-\delta^{18} \mathrm{O}$ diagram in Figure 3. We can find that the samples from the surface water are mostly falling on the global meteoric water line (GMWL). The samples from 


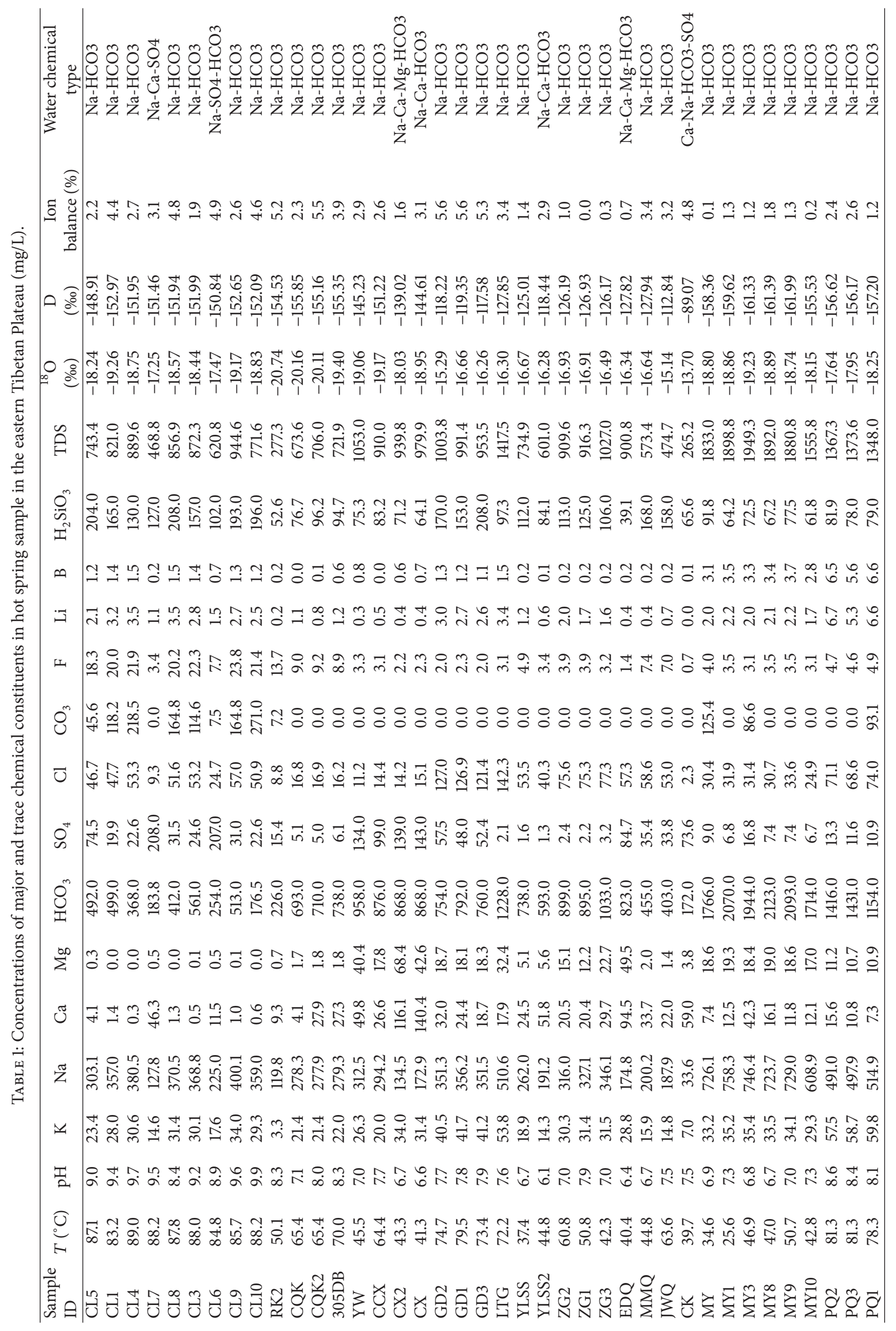




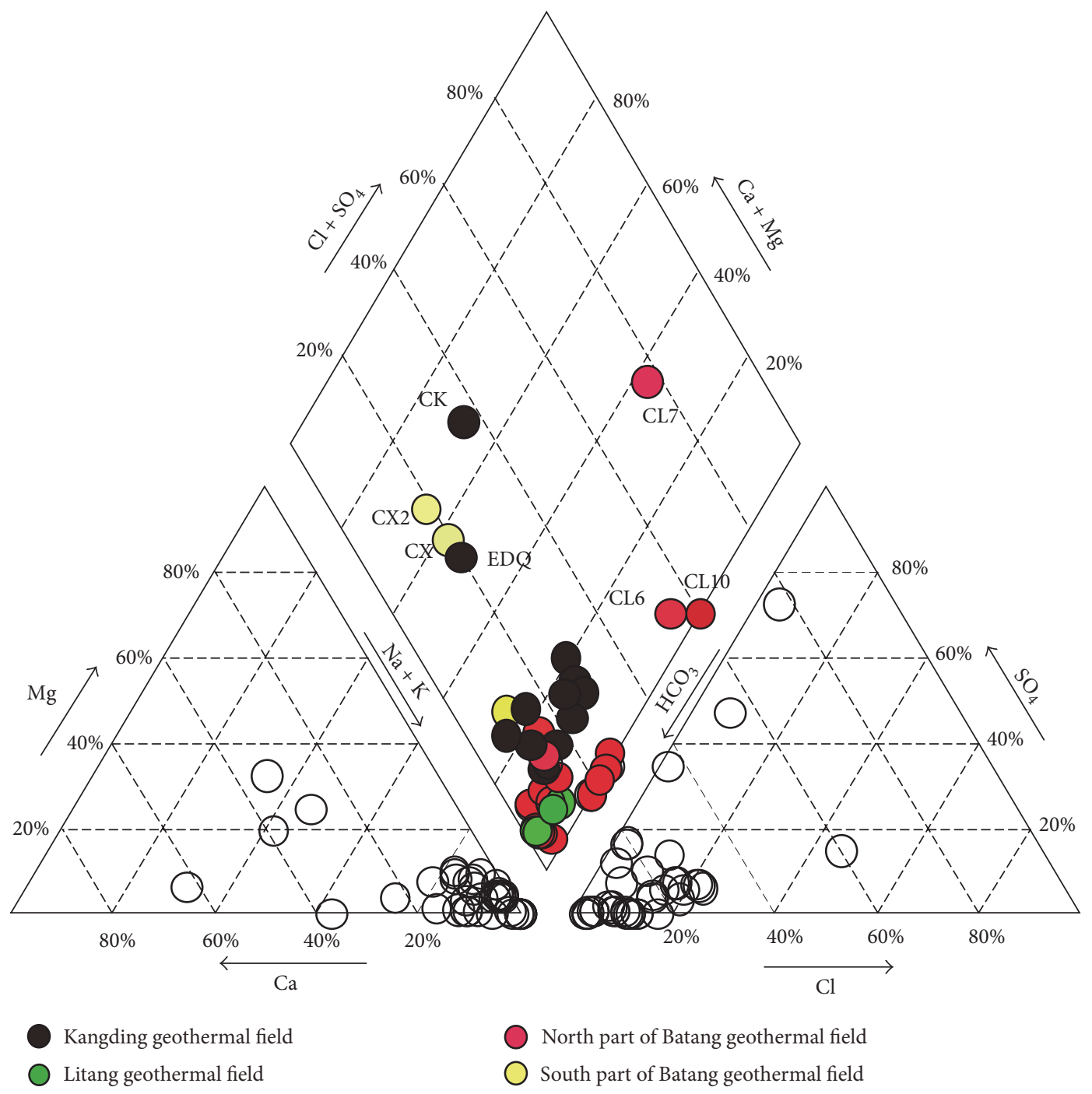

FIGURE 2: Piper diagram of the hot springs.

the Kangding geothermal field are heavier than the other two geothermal fields and are also close to the GMWL. For the samples from the Litang geothermal field, they show lighter hydrogen than the other two geothermal field samples. The hot springs in Batang geothermal fields can be divided into two different sections: the springs in the south part of the Batang geothermal field are lighter in hydrogen than the north part and the springs in the north part show significant oxygen-18 drift (Figure 3).

3.3. Result of Multivariate Statistical Analysis. Cluster analysis (CA) and factor analysis (FA) are used to identify the characteristics of the hydrochemical properties of hot springs in different fault zones and the possible hydrochemical evolution processes of these hot springs.

3.3.1. Cluster Analysis. K-means cluster analysis was made on all hot springs samples using their hydrochemical compositions. Based on the cluster analysis and corrected by discriminant analysis, the samples can be divided into three groups: the first group is CL spring group located in the north part of the Batang geothermal field; the second group is the Litang geothermal field; the third group consists of the hot springs from the Kangding geothermal field and the Batang geothermal field. From the relationship between Fluorine and Boron (Figure 4), we can find that the first group is in high concentration of Fluorine and low Boron hot spring water, which indicates that this groundwater is likely derived from the volcanic rocks $[29,30]$. The second group is characterized by high Boron concentration and low Fluorine concentration, and it also shows larger TDS than the other two groups (Figure 5); thus we infer that it may derive from the metamorphic rocks, that is, sand slate and phyllite rock. The third group is characterized by low Boron concentration and low Fluorine concentration, and it has relatively low TDS; thus we infer that it may derive from the mixture of shallow water. For the few hot springs such as CX, CX2, EDQ, CK1, and YLSS2 (Figure 5), they show high concentration of $\mathrm{Ca}^{2+}$, which indicate they may originate from the dissolution of carbonate. 


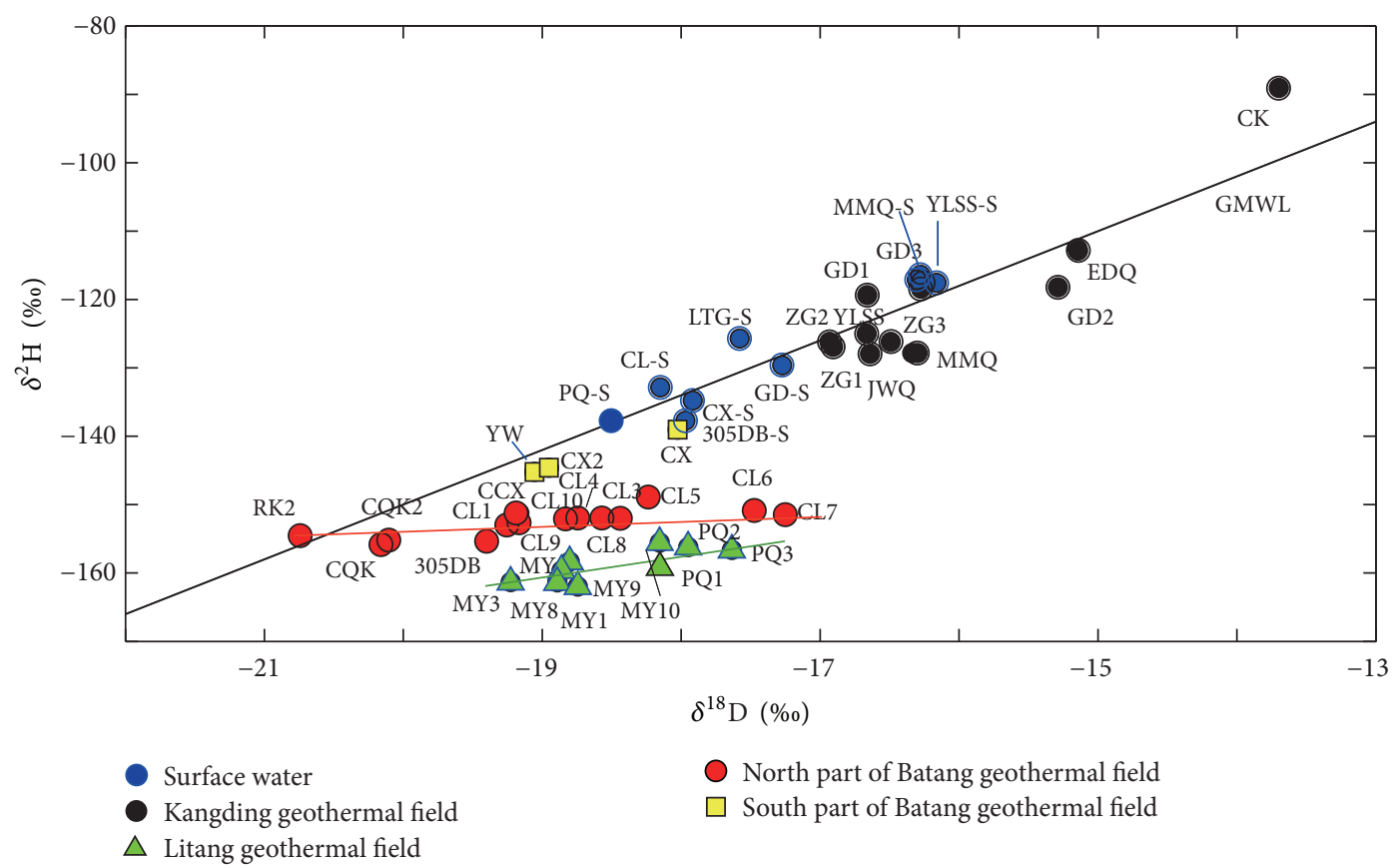

Figure 3: $\delta^{2} \mathrm{H}-\delta^{18} \mathrm{O}$ plot of hot springs in the eastern Tibetan Plateau.

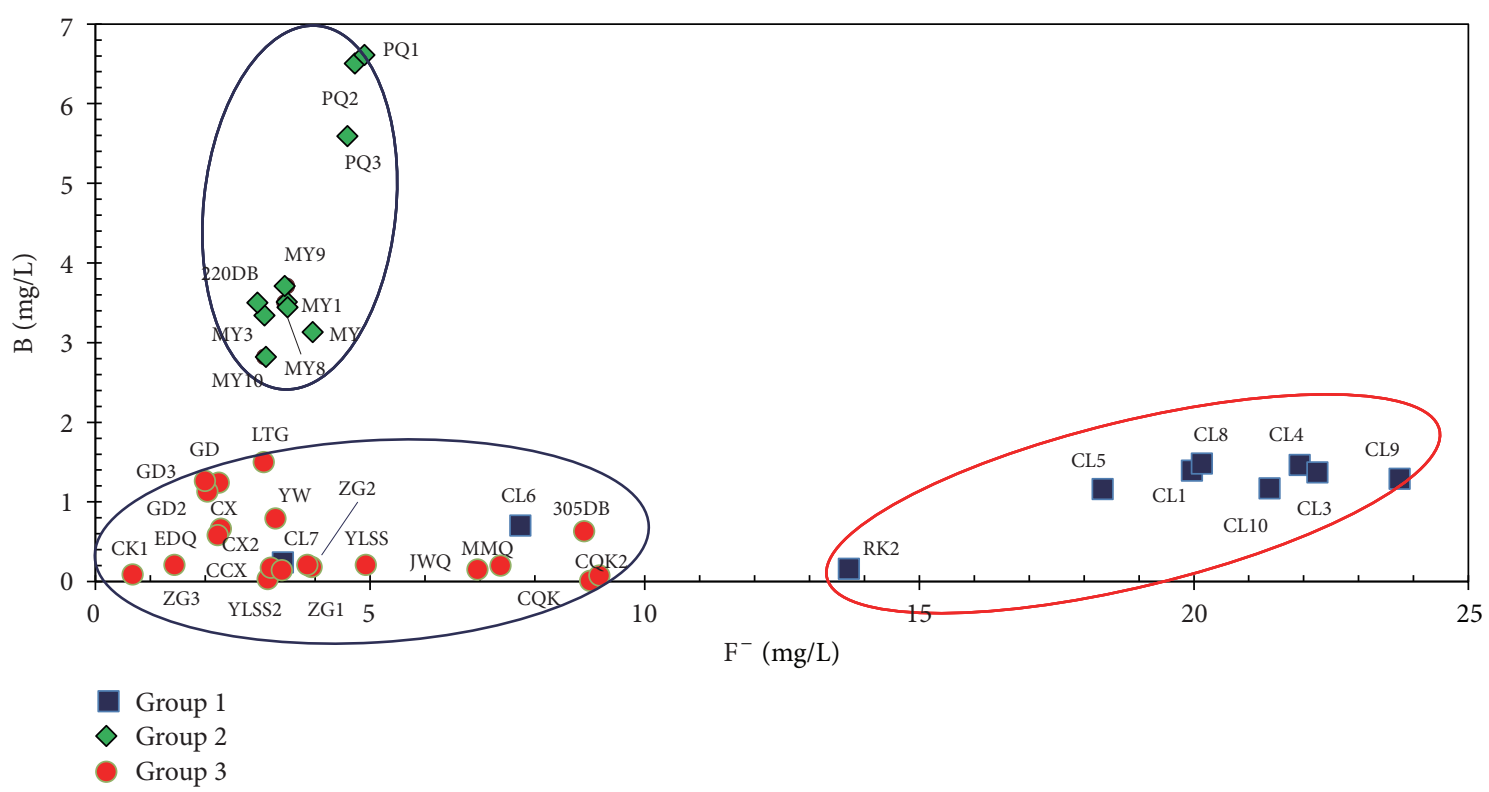

FIgURE 4: Relationship between F and B.

3.3.2. Factor Analysis. Factor analysis is an effective way in finding the relation between different variables. Here, we chose $\mathrm{Na}, \mathrm{Mg}, \mathrm{HCO}_{3}, \mathrm{SO}_{4}, \mathrm{Cl}$, TDS, T, and $\mathrm{pH}$ as major variables to do the analysis. SPSS 19.0 was employed to do the analysis; the result was listed in Table 2. Three factors were extracted based on the Kaizer criterion with a total cumulative variance of $83.1 \%$ (Table 2). Factor 1 possesses the largest portion of total variance $(37.47 \%)$ with high positive loadings for TDS (0.96), $\mathrm{HCO}_{3}(0.93)$, and $\mathrm{Na}(0.93)$. Factor 2 corresponds to a variance portion of $24.55 \%$ with high positive loadings for $\mathrm{Mg}(0.869)$ and $\mathrm{Ca}(0.868)$ and Factor
3 with positive loading for $\mathrm{T}(0.87)$ and $\mathrm{pH}(0.71)$, accounting for $21.08 \%$ of total variance (Table 3 ).

As TDS (0.96), $\mathrm{HCO}_{3}(0.93)$, and $\mathrm{Na}(0.93)$ have the high positive loading in Factor 1, the major hydrochemical processes could be explained as the water-rock interaction, which is dominant by the dissolution of sodium carbonate silicon, and can be described as the following reaction:

$$
\begin{gathered}
2 \mathrm{NaAlSi}_{3} \mathrm{O}_{8(\mathrm{~s})}+2 \mathrm{H}_{2} \mathrm{CO}_{3}+9 \mathrm{H}_{2} \mathrm{O} \longleftrightarrow \\
\mathrm{Al}_{2} \mathrm{Si}_{2} \mathrm{O}_{5}(\mathrm{OH})_{4(\mathrm{~s})}+2 \mathrm{Na}^{+}+2 \mathrm{HCO}_{3}^{-}
\end{gathered}
$$




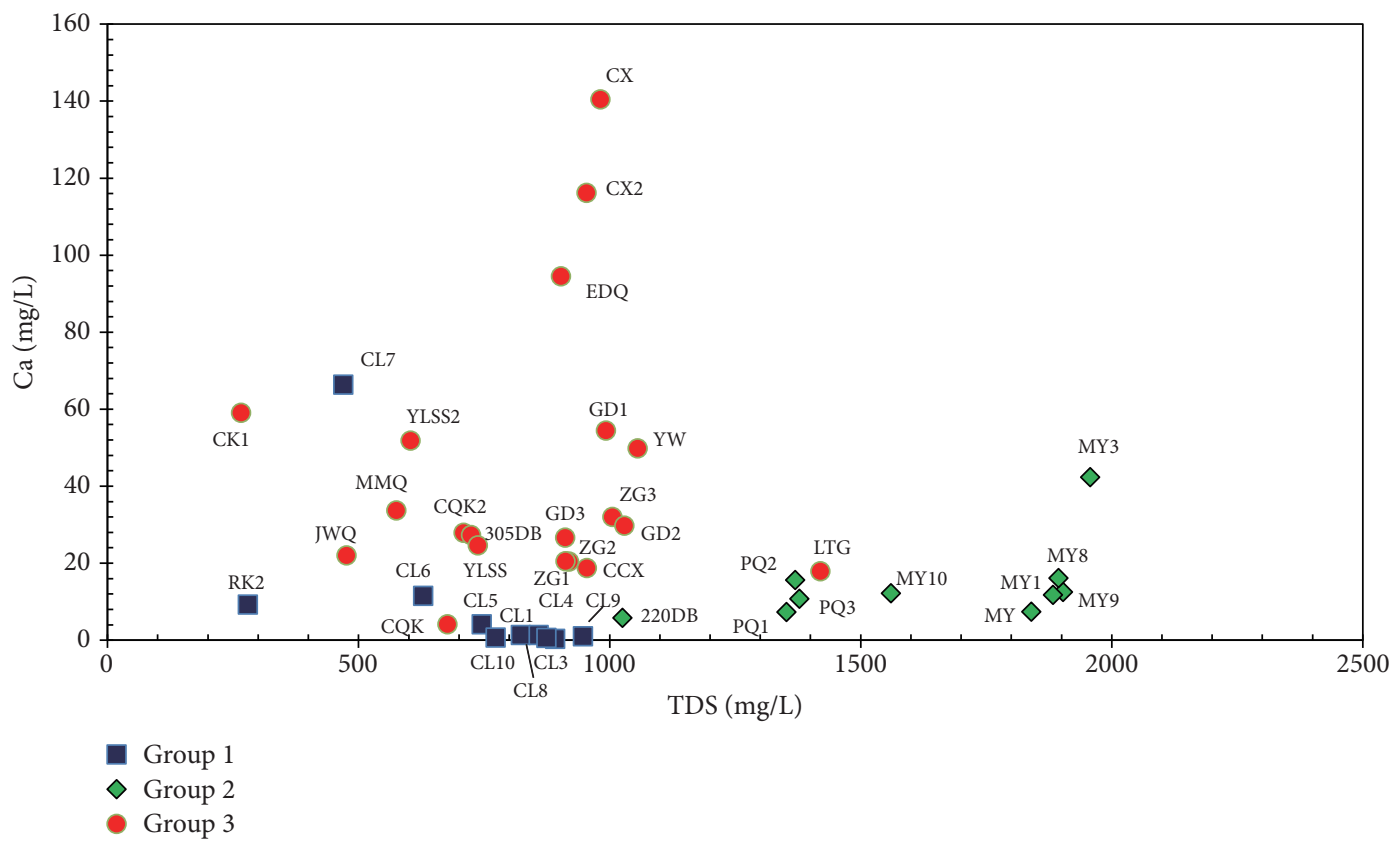

FIGURE 5: Relationship between Ca and TDS.

TABLE 2: Total variance explained.

\begin{tabular}{lccccccccc}
\hline \multirow{2}{*}{$\begin{array}{c}\text { Component } \\
\end{array}$} & \multicolumn{3}{c}{ Initial eigenvalue } & \multicolumn{2}{c}{ Extraction sum of squared loadings } & \multicolumn{2}{c}{ Rotation } \\
Eigenvalue & Variance\% & Cumulative\% & Eigenvalue & Variance\% & Cumulative\% & Eigenvalue & Variance\% & Cumulative\% \\
\hline 1.00 & 3.57 & 39.63 & 39.64 & 3.57 & 39.64 & 39.64 & 3.37 & 37.47 \\
2.00 & 2.79 & 30.98 & 70.62 & 2.79 & 30.98 & 70.62 & 2.21 & 24.55 \\
3.00 & 1.12 & 12.48 & 83.10 & 1.12 & 12.49 & 83.10 & 1.90 & 21.08 & 62.02 \\
4.00 & 0.99 & 11.01 & 94.12 & 0 & 0 & 0 & 0 & 0 & 0 \\
5.00 & 0.22 & 2.47 & 96.59 & 0 & 0 & 0 & 0 & 0 & 0 \\
6.00 & 0.16 & 1.75 & 98.34 & 0 & 0 & 0 & 0 & 0 & 0 \\
7.00 & 0.11 & 1.24 & 99.58 & 0 & 0 & 0 & 0 & 0 & 0 \\
8.00 & 0.04 & 0.40 & 99.98 & 0 & 0 & 0 & 0 & 0 & 0 \\
9.00 & 0.00 & 0.03 & 100.00 & 0 & 0 & 0 & 0 & 0 & 0 \\
\hline
\end{tabular}

Extraction method: Principal Component Analysis (PCA).

TABLE 3: Components and loading for varimax rotated factor matrix.

\begin{tabular}{lccc}
\hline Parameters & \multicolumn{3}{c}{ Component } \\
\hline TDS & $\mathbf{0 . 9 6 1}$ & 2 & 3 \\
$\mathrm{HCO}_{3}{ }^{-}$ & $\mathbf{0 . 9 3 2}$ & 0.066 & -0.012 \\
$\mathrm{Na}^{+}$ & $\mathbf{0 . 9 3 0}$ & -0.240 & -0.257 \\
$\mathrm{Mg}^{2+}$ & 0.335 & $\mathbf{0 . 8 6 9}$ & 0.083 \\
$\mathrm{Ca}^{2+}$ & -0.228 & $\mathbf{0 . 8 6 8}$ & -0.183 \\
$\mathrm{SO}_{4}{ }^{2-}$ & -0.492 & 0.632 & -0.294 \\
$T$ & -0.285 & -0.268 & 0.130 \\
$\mathrm{pH}^{-}$ & -0.349 & -0.394 & $\mathbf{0 . 8 7 0}$ \\
$\mathrm{Cl}$ & 0.325 & 0.091 & $\mathbf{0 . 7 1 3}$ \\
\hline
\end{tabular}

${ }^{*}$ The loadings over 0.70 are regarded as significant variables and are marked in bold.

For the three groups of the 39 hot spring samples, they are all approximately close to the ratio of $\mathrm{Na} / \mathrm{HCO}_{3}$ of $1: 1$ line, especially for the second group (Figure 6). The first group shows largest deviation from the 1:1 line; this is caused by the impaction of $\mathrm{pH}$; the $\mathrm{pH}$ in the first group ranges from 8.3 to 9.86 which lead to $\mathrm{HCO}_{3}{ }^{-}$changing into $\mathrm{CO}_{3}{ }^{2-}$ thus causing the lower $\mathrm{HCO}_{3}{ }^{-}$. The ratio in third group is a little higher than the $1: 1$ line (Figures 6 and 7).

Factor 2 indicates the cation exchange between $\mathrm{Na}^{+}$and $\mathrm{Ca}^{2+}$ and $\mathrm{Mg}^{2+}$, and the ratio of $(\mathrm{Ca}+\mathrm{Mg}) /\left(\mathrm{HCO}_{3}-\mathrm{Cl}-\mathrm{Na}\right)$ would be close to 1:1 line. As shown in Figure 8, samples in the third group show ratios close to the 1:1 line. With the increase of concentration of $\mathrm{Ca}+\mathrm{Mg}$, the samples become closer to the $1: 1$ line. In the lower concentration area, the samples are scattered and become closer to the $1: 1$ line in the high concentration area. Thus, we conclude that the $\mathrm{Ca}$ and $\mathrm{Mg}$ concentration are determined by the cation exchange with Na. During this process, $\mathrm{Na}$ will be exchanged into the aquifer and $\mathrm{Ca}$, and $\mathrm{Mg}$ will be exchanged into the groundwater, leading to the ratio of $\mathrm{Na} / \mathrm{Cl}+\mathrm{HCO}_{3}$ in third group being a little higher than the $1: 1$ line. Thus, combining with the low 


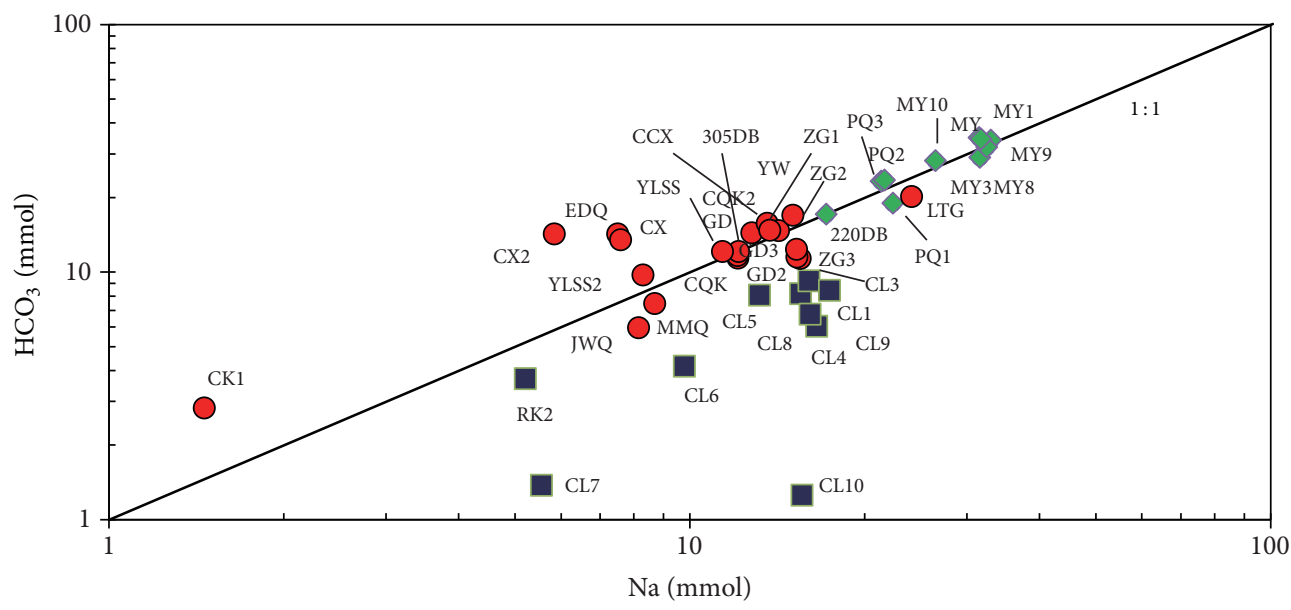

Group 1

Group 2

Group 3

FIgURE 6: Relationship between $\mathrm{Na}^{+}$and $\mathrm{HCO}_{3}{ }^{-}$.

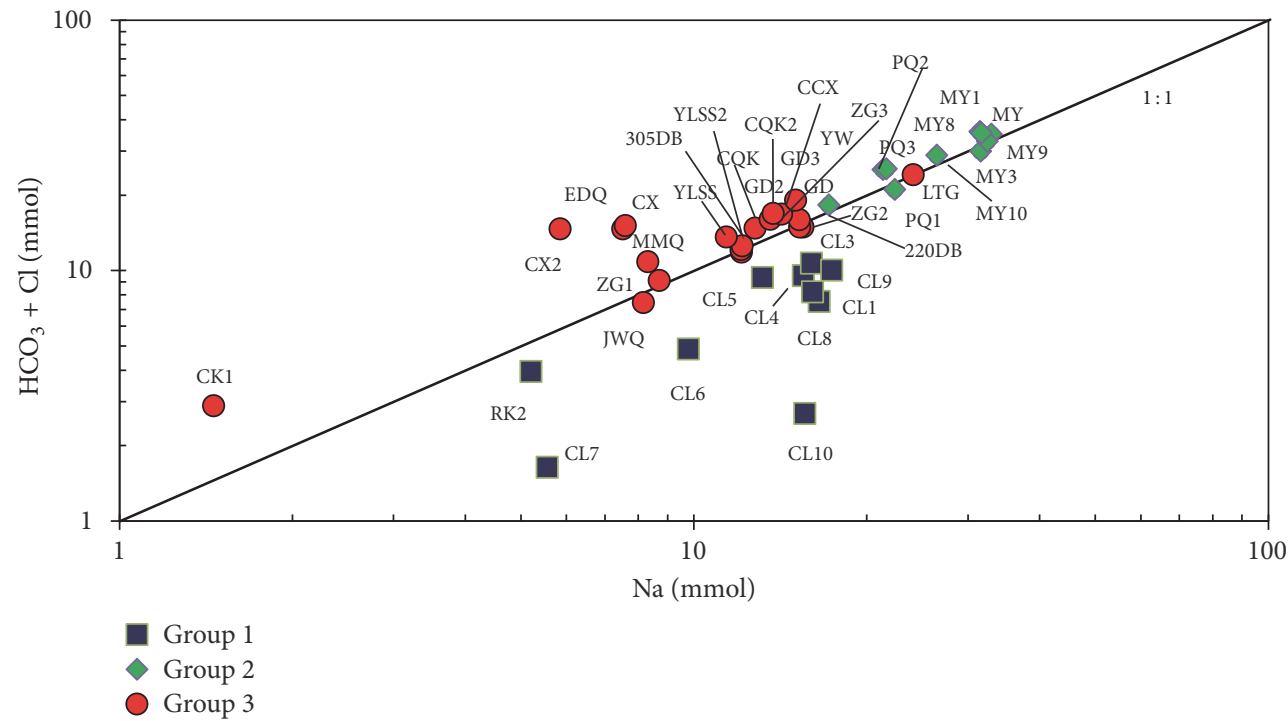

Figure 7: Relationship between $\mathrm{Na}^{+}$and $\mathrm{HCO}_{3}+\mathrm{Cl}$.

Boron concentration and low Fluorine concentration in the third group, we conclude that the thermal water samples in the third group are caused by the mixture of shallow water. The distribution of factor scores also shows that the third group has the highest score in Factor 2 (Figure 9), indicating that the factor has the largest effect on the third group.

Factor 3 has the positive loading of $\mathrm{pH}$ and $\mathrm{T}$, which indicates that the samples are affected by the water environment. The first group shows largest Factor 2 score (Figure 10). This is coinciding with the high temperature in the first group (CL spring groups).

\section{Discussion}

By using the cluster analysis, we can divide the hot springs into three groups: the first group is located in the north part of the Batang geothermal field, the second group is located in the Litang geothermal field, and the third group is located in the Kangding geothermal field and the south part of the Batang geothermal field.

The chemical analysis shows that the hot springs are dominant by the $\mathrm{Na}-\mathrm{HCO}_{3}$ type in Kangding geothermal field, Litang geothermal field, and north Batang geothermal field; only the hot springs in the south Batang geothermal field show other water chemical types. In volcanic rock area, the $\mathrm{Na}-\mathrm{HCO}_{3}$ type water is usually derived from the leaching of sodium carbonate silicon rocks. Extensive occurrences of magmatic rocks are a characteristic geological feature of the eastern Tibetan Plateau, and the springs are mainly exposed in the granite rock or in the contact zone with granite; thus it is expected that $\mathrm{Na}-\mathrm{HCO}_{3}$ type is the dominant water chemical type in this area. The factor analysis also 


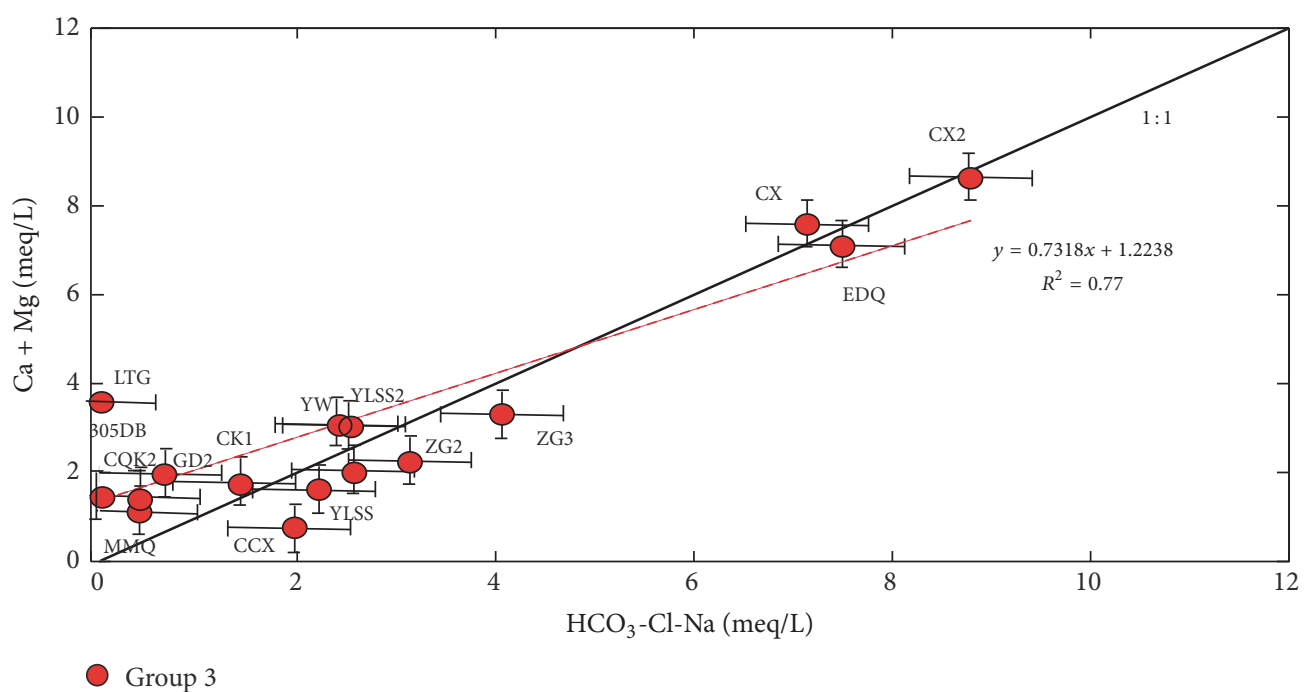

Figure 8: Relationship between $\mathrm{Ca}+\mathrm{Mg}$ and $\mathrm{HCO}_{3}-\mathrm{Cl}-\mathrm{Na}$.

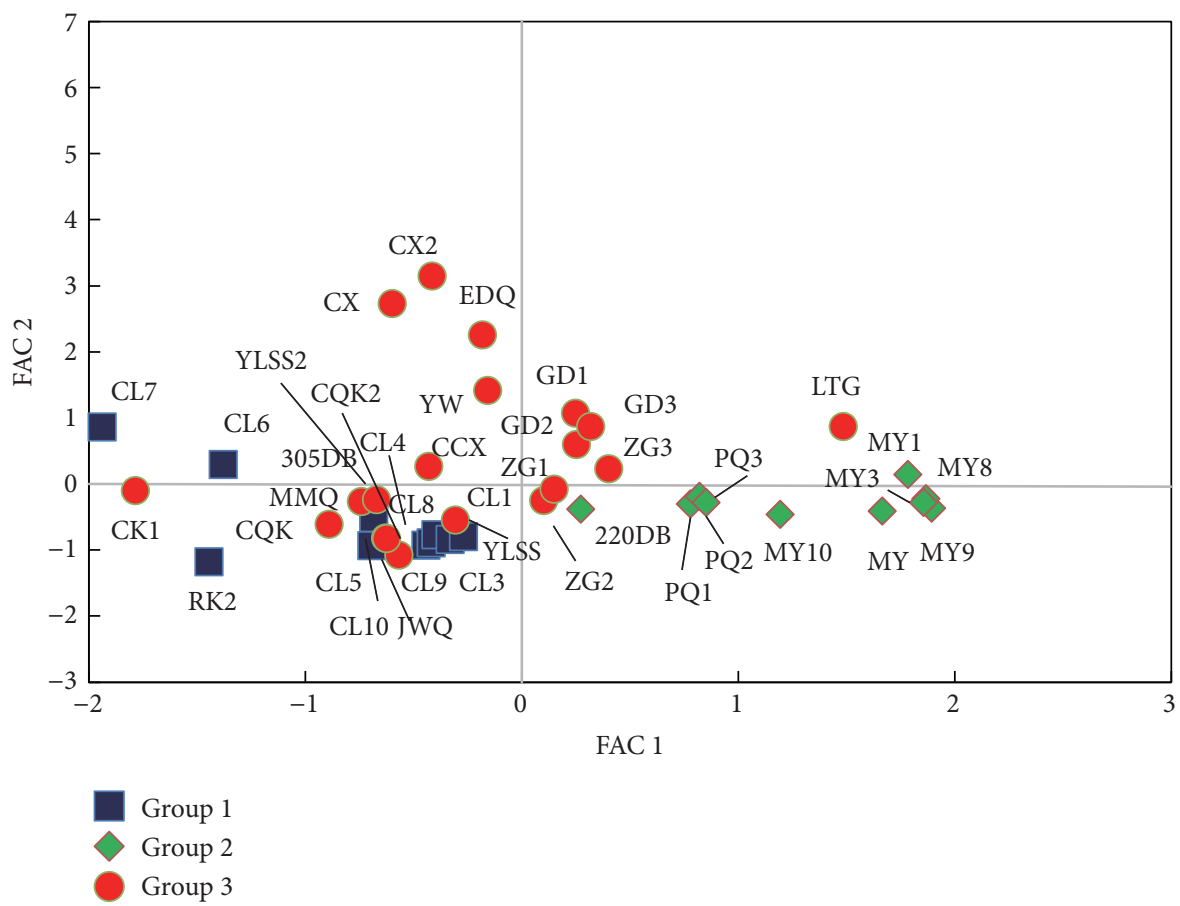

FIGURE 9: Distribution of score of Factor 1 and Factor 2 of the hot springs.

shows that the dissolution of sodium carbonate silicon is the major hydrochemical process for these springs. Factor 2 indicates that the cation exchange between $\mathrm{Ca}, \mathrm{Mg}$, and $\mathrm{Na}$ is the major hydrochemical process that leads to the other water chemical types in this area, especially for the spring in the third group. The relationship of $\mathrm{Ca}+\mathrm{Mg} / \mathrm{HCO}_{3}-\mathrm{Cl}-$ $\mathrm{Na}$ also supports this speculation. Particularly, we find that $\mathrm{Na}, \mathrm{Ca}$, and $\mathrm{Mg}$ are the major cations in these springs: $\mathrm{CX}$, $\mathrm{CX}_{2}, \mathrm{CL7}, \mathrm{CK}, \mathrm{EDQ}$, and YLSS2. Seeing from the lithology, we can find carbonatite rock exposed in these springs [3]; thus cation exchanges with $\mathrm{Na}$ can be significant in these springs.
The ${ }^{18} \mathrm{O}$ and $\mathrm{D}$ isotope data show that the springs in Kangding geothermal field are close to the GMWL, indicating that they are mainly deriving from the precipitation. The Litang geothermal field shows the lightest hydrogen and deviates largely from the surface water (Figure 3), indicating that they are not recharged from local precipitation. The springs in the north part of the Batang geothermal field show a significant ${ }^{18} \mathrm{O}$ drift, and they are lighter in hydrogen value than the surface water nearby, indicating the groundwater has undergone a quite long water-rock interaction process and may originate from snow melt in the high mountains. The hot springs in the south part of the Batang geothermal 


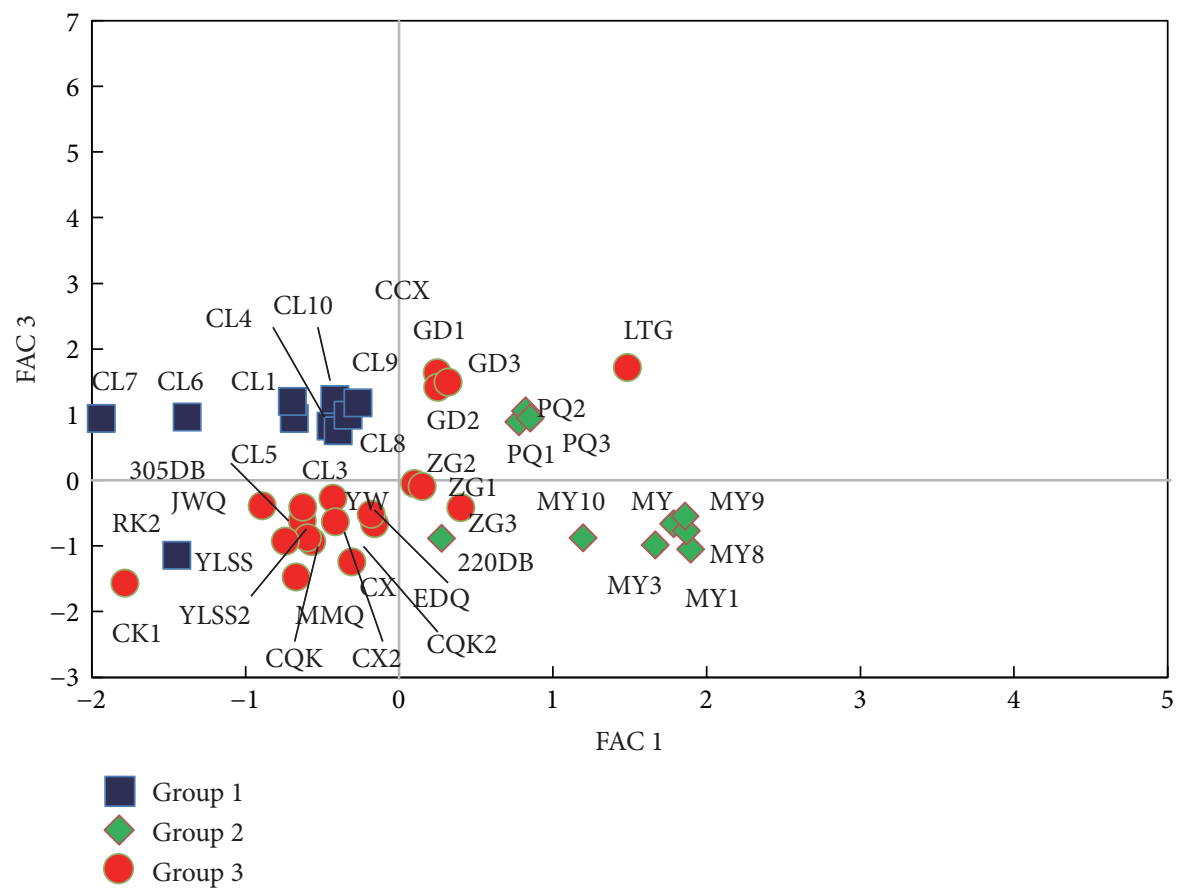

FIgURE 10: Distribution of score of Factor 1 and Factor 3 of the hot springs.

field show similar isotope value to the surface water nearby, indicating they receive recharge from the surface water. Thus, from the viewpoint of isotope data, we also can conclude that the hot springs in the third group (the Kangding geothermal field and south part of Batang geothermal field) may originate from the mixture of shallow groundwater, consistent with the multivariate analysis.

\section{Conclusions}

We analyzed the chemical and isotopic characteristic of the hot springs located in the eastern Tibetan Plateau. By cluster analysis, we can divide these hot springs into three groups based on their locations: (1) the north part of the Batang geothermal field, (2) the Litang geothermal field, and (3) the Kangding geothermal field and the south part of the Batang geothermal field. The hot springs in the first group mainly originate from the volcanic rock and the springs in the second group originate from the metamorphic rock while the springs in the third group originate from the result of mixture of shallow water. Water-rock interaction, cation exchange, and the water environment are the three dominant factors that control the hydrochemical evolution process in the eastern Tibetan Plateau. These results are also in well agreement with the isotopic and chemical analysis.

\section{Conflicts of Interest}

The authors declare that they have no conflicts of interest.

\section{Acknowledgments}

The authors greatly thank Xianhe Yang and Haijiang Niu for their help in the field. This work is supported by the
National Natural Science Foundation of China (41602266, U1602233), the Fundamental Research Funds for the Central Universities (2652013088), and the Beijing Talents Funds (2016000020124G110).

\section{References}

[1] A. Yin and T. M. Harrison, "Geologic evolution of the himalayan-tibetan orogen," Annual Review of Earth \& Planetary Sciences, vol. 28, no. 28, pp. 211-280, 2003.

[2] X. Tang, J. Zhang, Z. Pang, S. Hu, Y. Wu, and S. Bao, "Distribution and genesis of the eastern Tibetan Plateau geothermal belt, western China," Environmental Earth Sciences, vol. 76, no. 1, p. 31, 2017.

[3] W. Tong and M. Zhang, Chorography of Spring in the Hengduan Mountainous District, Science Press, Beijing, 1994.

[4] Y. Cao, H. Li, Z. Liu, D. Yuan, and L. Shen, "Comparison of geochemical features of warm springs between Chongqing and Kangding," Carsologica Sinica, vol. 25, no. 2, pp. 112-120, 2006.

[5] Z. Chen, X. Zhou, J. Du et al., "Hydrochemical characteristics of hot spring waters in the Kangding district related to the Lushan MS = 7.0 earthquake in Sichuan, China," Natural Hazards and Earth System Sciences, vol. 15, no. 6, pp. 1149-1156, 2015.

[6] V. K. Saxena and N. C. Mondal, Application of Water Chemistry for the Estimation of Aquifer Temperature, Puttur Hot Spring, India, Karnatka, 2003.

[7] Z. Xiaocheng, "Gas geochemitry in western sichuan related to 12 May 2008 wenchuan Ms8.0 earthquake, science and technology of China, Hefei," in Science and Technology of China, 2011.

[8] Q. Guo and Y. Wang, "Geochemistry of hot springs in the Tengchong hydrothermal areas, Southwestern China," Journal of Volcanology and Geothermal Research, vol. 215-216, pp. 61-73, 2012.

[9] C. S. Jang, J. S. Chen, Y. B. Lin, and C. W. Liu, "Characterizing hydrochemical properties of springs in Taiwan based on their 
geological origins," Environmental Monitoring Assessment, vol. 184, no. 1, pp. 63-75, 2012.

[10] X. Zhang, Q. Guo, M. Liu et al., "Hydrogeochemical processes occurring in the hydrothermal systems of the Gonghe-Guide basin, northwestern China: critical insights from a principal components analysis (PCA)," Environmental Earth Sciences, vol. 75, no. 16, article no. 1187, 2016.

[11] D. V. Sarwade, M. V. Nandakumar, M. P. Kesari, N. C. Mondal, V. S. Singh, and B. Singh, "Evaluation of sea water ingress into an Indian atoll," Environmental Geology, vol. 52, no. 8, pp. 14751483, 2007.

[12] D. K. Kreamer, V. F. Hodge, I. Rabinowitz, K. H. Johannesson, and K. J. Stetzenbach, "Trace element geochemistry in water from selected springs in Death Valley National Park, California," Ground Water, vol. 34, no. 1, pp. 95-103, 1996.

[13] N. Lambrakis, A. Antonakos, and G. Panagopoulos, "The use of multicomponent statistical analysis in hydrogeological environmental research," Water Research, vol. 38, no. 7, pp. 1862-1872, 2004.

[14] N. C. Mondal, V. P. Singh, S. Singh, and V. S. Singh, "Hydrochemical characteristic of coastal aquifer from Tuticorin, Tamil Nadu, India," Environmental Monitoring and Assessment, vol. 175, no. 1-4, pp. 531-550, 2011.

[15] D. Machiwal and M. K. Jha, "Identifying sources of groundwater contamination in a hard-rock aquifer system using multivariate statistical analyses and GIS-based geostatistical modeling techniques," Journal of Hydrology: Regional Studies, vol. 4, pp. 80110, 2015.

[16] G. Papatheodorou, N. Lambrakis, and G. Panagopoulos, "Application of multivariate statistical procedures to the hydrochemical study of a coastal aquifer: An example from Crete, Greece," Hydrological Processes, vol. 21, no. 11, pp. 1482-1495, 2007.

[17] S. K. Swanson, J. M. Bahr, M. T. Schwar, and K. W. Potter, “Twoway cluster analysis of geochemical data to constrain spring source waters," Chemical Geology, vol. 179, no. 1-4, pp. 73-91, 2001.

[18] N. C. Mondal, V. P. Singh, V. S. Singh, and V. K. Saxena, "Determining the interaction between groundwater and saline water through groundwater major ions chemistry," Journal of Hydrology, vol. 388, no. 1-2, pp. 100-111, 2010.

[19] X. Zhang, H. Qian, H. Wu, J. Chen, and L. Qiao, "Multivariate analysis of confined groundwater hydrochemistry of a longexploited sedimentary basin in northwest China," Journal of Chemistry, vol. 2016, Article ID 3812125, 2016.

[20] H. Suk and K.-K. Lee, "Characterization of a ground water hydrochemical system through multivariate analysis: Clustering into ground water zones," Ground Water, vol. 37, no. 3, pp. 358-366, 1999.

[21] K. Dragon and J. Gorski, "Identification of groundwater chemistry origins in a regional aquifer system (Wielkopolska region, Poland)," Environmental Earth Sciences, vol. 73, no. 5, pp. 21532167, 2015.

[22] J. Q. Deng and Y. X. Lin, "Propagation of the deformation and growth of the Tibetan-Himalayan orogen: A review," EarthScience Reviews, vol. 143, no. 1, pp. 36-61, 2015.

[23] W. Min, Z. K. Shen, W. J. Gan et al., "GPS monitoring of temporal deformation of the Xianshuihe fault," Science in China, Series D: Earth Sciences, vol. 51, no. 9, pp. 1259-1266, 2008.

[24] E. Papadimitriou, X. Wen, V. Karakostas, and X. Jin, "Earthquake triggering along the xianshuihe fault zone of western Sichuan, China," Pure and Applied Geophysics, vol. 161, no. 8, pp. 1683-1707, 2004.
[25] X. Xu, X. Wen, G. Yu, R. Zheng, H. Luo, and B. Zheng, "Average slip rate, earthquake rupturing segmentation and recurrence behavior on the Litang fault zone, western Sichuan Province, China," Science in China, Series D: Earth Sciences, vol. 48, no. 8, pp. 1183-1196, 2005.

[26] R. J. Zhou, G. X. Chen, Y. Li et al., "Research on active faults in litang-batang region, western sichuan province, and the seismogenic structures of the 1989 batang m6.7 earthquake swarm," Seismology Geology, vol. 27, no. 1, pp. 31-43, 2005.

[27] S. J. Phillips, Acceleration of K-Means and Related Clustering Algorithms, vol. 2409, Springer Berlin Heidelberg, Berlin, Heidelberg, 2002.

[28] S. M. Yidana, D. Ophori, and B. Banoeng-Yakubo, "A multivariate statistical analysis of surface water chemistry data-The Ankobra Basin, Ghana," Journal of Environmental Management, vol. 86, no. 1, pp. 80-87, 2008.

[29] S. Chatterjee, A. Sarkar, A. S. Deodhar et al., "Geochemical and isotope hydrological characterisation of geothermal resources at Godavari valley, India," Environmental Earth Sciences, vol. 76, no. 2, 2017.

[30] C. P. s. L. A. T. (CPLA), 1:500000 Hydrogeological Survey Report, Geological Publishing House, Beijing, China, 1980. 

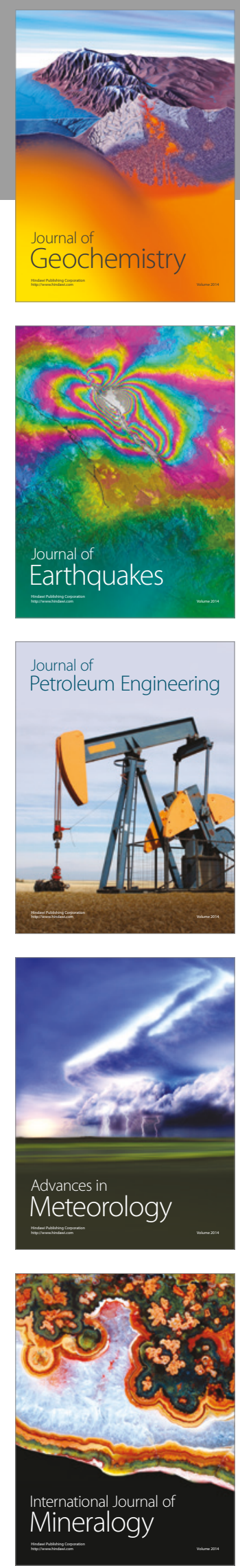
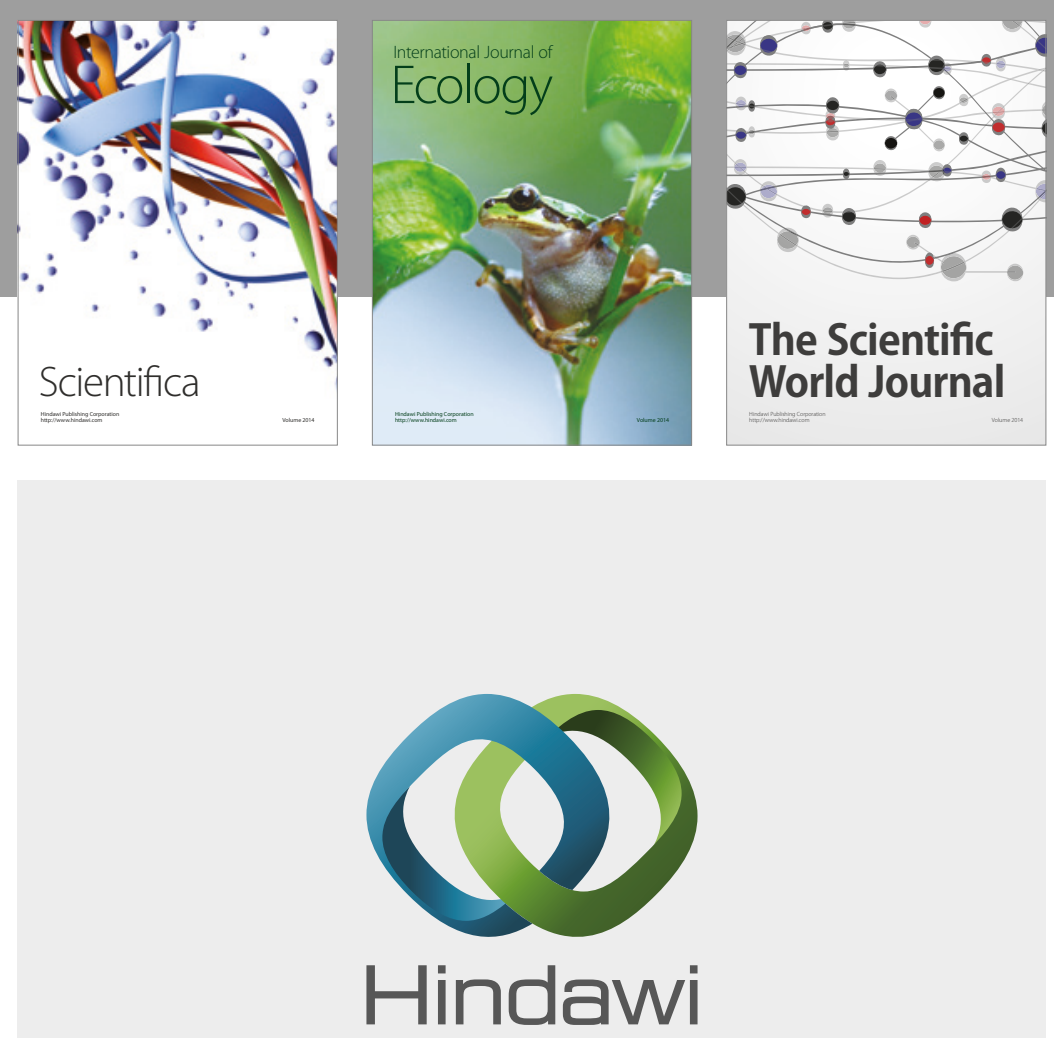

Submit your manuscripts at

https://www.hindawi.com
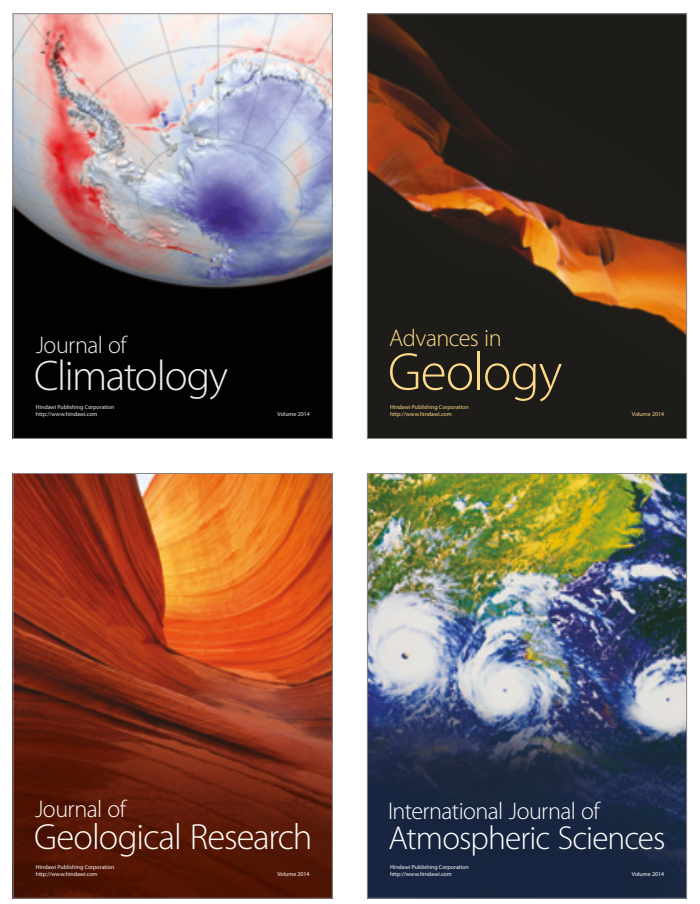

The Scientific

World Journal
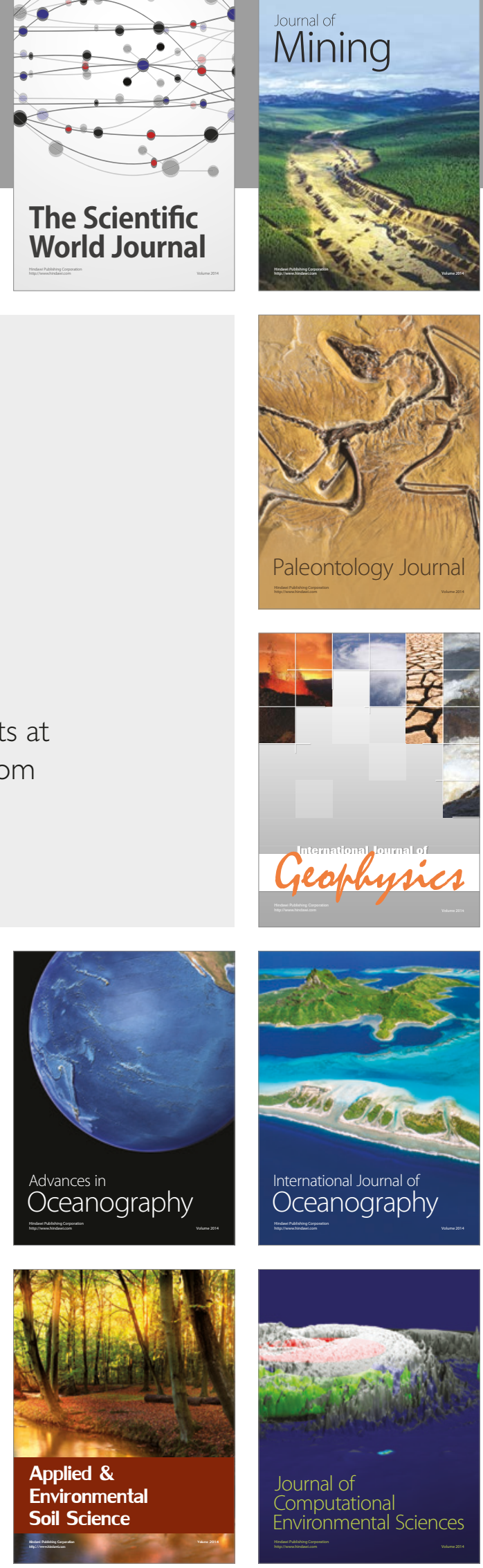